\title{
Barriers to disclosure of disease in HIV-infected women: a qualitative study
}

\author{
Sara Esmaelzadeh Saeieh ${ }^{1}$, Abbas Ebadi² ${ }^{2}$ Zohreh Mahmoodi³ ${ }^{3}$ Minoo Mohraz ${ }^{4}$, \\ Alireza Nikbakht Nasrabadi ${ }^{5}$, Zahra Behboodi Moghadam ${ }^{6}$ \\ ${ }^{1}$ Social Determinants of Health Research Center, Alborz University of Medical Sciences, Karaj, Iran \\ ${ }^{2}$ Behavioral Sciences Research Center, Nursing School, Baqiyatallah University of Medical Sciences, Tehran, Iran \\ ${ }^{3}$ Non-communicable Diseases Research Center, Alborz University of Medical Sciences, Karaj, Iran \\ ${ }^{4}$ Iranian Research Center of HIV/AIDS, Iranian Institute for Reduction of High-Risk Behaviors, Tehran University of Medical \\ Sciences, Tehran, Iran \\ ${ }^{5}$ Department of Medical Surgical, School of Nursing and Midwifery, Tehran University of Medical Sciences, Tehran, Iran \\ ${ }^{6}$ Department of Reproductive Health, School of Nursing and Midwifery, Tehran University of Medical Sciences, Tehran, Iran
}

\begin{abstract}
Introduction: Disclosure of human immunodeficiency virus (HIV) status reduces high-risk behaviors. Also, non-disclosure of HIV status plays the most important role in the spread of disease and the occurrence of new cases. Given the increasing prevalence of HIV among women and the increase in the transmission of disease through sexual relationships, HIV-positive women are the most vulnerable group in society who are exposed to high-risk sexual behaviors. Therefore we conducted a qualitative study on non-disclosure experiences in Iranian women.

Material and methods: This qualitative study was conducted in 2015. Fifteen HIV-infected women who referred to Imam Khomeini Hospital Consultation Center for clients with risky behavior participated in this study. The data were collected through a semi-structured interview. Data were analyzed by conventional content analysis.

Results: Disclosure of HIV status was classified based on the experiences of the participants in two main categories: fear of rejection and community construction of HIV. Fear of rejection has two sub-categories: 1) rejection by partner, 2) rejection by family. The community construction of HIV has three sub-categories: 1) discrimination in society, 2) social stigma, and 3) traditional environment for health services.

Conclusions: The results of this study showed that women with HIV have a lot of problems in disclosing their disease status. Therefore, interventions for acceptance of HIV patients by their relatives and the provision of counseling services by health care providers are essential for the disclosure of HIV status by infected people.
\end{abstract}

HIV AIDS Rev 2018; 17, 1: 12-17 DOI: https://doi.org/10.5114/hivar.2018.72906

Key words: disclosure, HIV, Iranian women, qualitative research.

\begin{abstract}
Address for correspondence: Dr. Zahra Behboodi Moghadam, Department of Reproductive Health, Nursing and Midwifery School, Tehran University of Medical Sciences, Tehran, Iran, e-mail: behboodi@tums.ac.ir
\end{abstract}

Article history:

Received: 19.10.2017

Received in revised form: 22.10.2017

Accepted: 31.10.2017

Available online: 17.01.2018
International Journal of HIV-Related Problems

HIV \& AIDS

R e vi e w 


\section{Introduction}

The number of human immunodeficiency virus (HIV) patients has been reported as 34949 until April 2017 in Iran, of whom $84 \%$ are male and $16 \%$ are female. Fifty-four percent of the cases are in the age group of 21-35 years, indicating that more than $50 \%$ of the cases occur when an individual is sexually active and only in the first three months of the year 2016 while $34 \%$ of the patients were women and $66 \%$ were men. The rates of transmission through drug addiction by injection $39 \%$, transmission through sexual relationship $41 \%$, and transmission from mother to child $3 \%$ have been reported, while in $17 \%$ of the cases the method of transmission has not been reported. The use of common narcotic drugs and syringes has been the most common way of transmitting the virus over the last few years; however, today sexual transmission has exceeded all other methods [1]. In Iran, most infected women have been infected through their sexual partner and unfortunately have infected their children [2]. The virus transmission rate can be affected by the disclosure of HIV status and is an effective strategy for controlling the spread of the virus [3]. Disclosing the status of the infection reduces the transmission of HIV by reducing the prevalence of high-risk behaviors due to greater awareness of infection prevention [4]. Non-disclosure of the disease plays the most important role in the spread of HIV and the occurrence of new cases [5]. The disclosure of the sex partner's status is the responsibility of each infected person. This is the most effective prevention method. One of the causes of lack of condom usage in sexual relationships is lack of awareness of the sex partner's status [6]. The disclosure of HIV status as a voluntary or non-voluntary decision is a complex process, in which the person reports his/her status of the disease along with the cause, time, and place [7]. The results of many studies indicate that the incidence rate of disclosure status of disease is between $32.7 \%$ and $92.7 \%$ and have also shown a negative reaction to women more than men [8]. Discussion about the discovery of the disease has applications in both individual health and general health. Many studies have noted the benefits and disadvantages associated with the disclosure of the disease. Disclosure of the disease is associated with safe sexual behavior, desire for treatment, and the provision of supportive services. On the other hand, disclosure of the HIV status may be accompanied by stigma, discrimination, rejection, violence, regret, feelings of shame, isolation and exposure to judgment by others $[9,10]$. Despite the importance of this issue, the time and manner of disclosing the HIV status and its consequences remain unknown and require the infor-

Table 1. Sample of interview questions

\begin{tabular}{l}
\hline Can you tell us about the HIV diagnosis experience? \\
\hline Can you comment on the disclosure of the disease to others? \\
\hline Can you report your experience of disclosing the disease?
\end{tabular}

mation and strategies appropriate for people with HIV [11]. Sarovich et al. presented two theories about the process of disclosure of the disease: 1) advanced disease theory, 2) the theory of consequences. In the first theory, it is suggested that infected patients report their HIV status when the disease has progressed and it is impossible to hide. In the second theory, the decision to disclose the disease recommends weighing the advantages against disadvantages. Both of these theories have been criticized due to the concentrating on the endpoint of the disease and ignoring the consequences of non-disclosure of the disease [12]. The method and rate of HIV disclosure vary in different cultures. The results of studies in several African countries have shown that the rate of disclosure to sex partners is very low [13]. Results of a study in Iran show that more than half of the participants disclose their HIV infection status to at least one family member [14]. The results of studies in other countries have also shown that people with HIV tend to disclose their status to their friends [15]. A group of strategies which are presented with the aim of reducing or stopping the spread of HIV include the ability to improve safe sexual relationships, safe usage of injectable drugs and the disclosure of disease among people with HIV [16]. Given the increasing prevalence of HIV among women, the increase in the transmission of disease through sexual relationships and the increase in the transmission of the virus to infants born to infected mothers, HIV-positive women are the most vulnerable group in society who are exposed to high-risk sexual behaviors [17]. Therefore, the need to conduct a qualitative study on non-disclosure experiences in Iranian women is necessary.

\section{Material and methods}

This study was conducted as qualitative research. Data were analyzed through a content analysis approach. In this study, data were collected from participants without imposing perspectives. Data were collected through semi-structured interviews. The aim of this study was to explore barriers of HIV status disclosure in HIV-positive women.

In this study, 15 Iranian women with HIV were enrolled using purposeful sampling and consulting with caregivers at the high-risk behaviors center of Imam Khomeini Hospital in Tehran. In the present study, the data collection lasted from October 2015 to May 2016. The criteria for entering the study were 15-49 years old and having sexual activity, lack of severe addiction to the extent that they were able to respond and not having a psychiatric disease diagnosed by a physician. The main method of data collection was a semi-structured interview, and data saturation was reached with 15 people. The interviews commenced with open questions and continued with exploratory questions. Examples of the interview questions are listed in Table 1.

After obtaining permission from the ethics committee of Tehran University of Medical Sciences, No. 92/d/13039/2639, the samples were selected purposefully and with maximum variety. All participants were aware of the purpose and method of the study and informed consent obtained from 
all respondents. The interviews were conducted by the corresponding author of the paper and the first author and recorded with the permission of the participants. After finishing each interview, they were transcribed and then coded. After analyzing each interview, the next interview was conducted. The interview time was 45 to 90 minutes, on average about 60 minutes, and all women were interviewed in a private room. At the beginning of the interview, each participant answered some questions about their education, type of infection, status of their marriage, number of their children, duration of the disease and the status of their spouse.

The information was analyzed by the conventional content analysis approach and was also processed using the Garniehamand Lundman method as follows [18]:

1. First, the interviews were completed and after several readings, a general concept was obtained.

2. The text of the interviews was divided into several units of meaning and then coded.

3. The units of meaning were summarized and compressed and extracted in the code form.

4. The codes were grouped based on the similarities and differences in the similar categories and sub-categories.

5. Categories were reorganized and extracted from the latent content of interview texts.

The extracted codes were managed through the MAXQDA10 text data organization software. To ensure the accuracy of the data, Lincoln and Guba's proposed criteria of credibility, dependability, confirmability and transferability were used [19].

In order to check credibility, member checking and peer review was conducted, so that a number of participants who were asked to view the completed text and interviews and extracts from them could see whether they were based on their experiences or not. In peer review, interviews were coded by reviewers and all members of the research consulted and collaborated over all stages of the analysis. Data transferability was checked by providing a complete file of participant characteristics, collection method, and analytical data analysis, with examples of participants' interviews to provide the possibility for others to conduct research.

\section{Results}

The demographic characteristics of the participants in the study are presented in Table 2 .

In the analysis of interviews, the following classes were extracted (Table 3).

The fear of rejection, which included two subcategories, rejection by the family and rejection by the partner. Community construction of HIV, which includes three subcategories: 1) discrimination in society, 2) social stigmatization, 3) traditional environment for health services.

\section{Fear of rejection}

The fear of rejection and acts of violence against them is one of the sub-categories of non-disclosure of the disease.
Table 2. Characteristics of the study population

\begin{tabular}{|c|c|}
\hline Factor & $n$ \\
\hline \multicolumn{2}{|l|}{ Age (years) } \\
\hline $22-27$ & 6 \\
\hline $28-33$ & 3 \\
\hline $34-39$ & 5 \\
\hline $40-45$ & 1 \\
\hline \multicolumn{2}{|l|}{ Marital status } \\
\hline Single & 1 \\
\hline Married & 12 \\
\hline Divorced & 2 \\
\hline \multicolumn{2}{|l|}{ Education } \\
\hline Primary or less & 2 \\
\hline Secondary & 4 \\
\hline Diploma & 7 \\
\hline University & 2 \\
\hline \multicolumn{2}{|l|}{ Job } \\
\hline Homemaker & 11 \\
\hline Employee & 2 \\
\hline Unemployed & 1 \\
\hline Informal job & 1 \\
\hline \multicolumn{2}{|l|}{ Transmission } \\
\hline Extramarital sexual relationship & 3 \\
\hline Infected husband & 9 \\
\hline Unknown & 3 \\
\hline \multicolumn{2}{|l|}{ Time of diagnosis, years } \\
\hline$<1$ & 1 \\
\hline $1-5$ & 8 \\
\hline $6-10$ & 3 \\
\hline $11-15$ & 2 \\
\hline \multicolumn{2}{|l|}{ Partner/Husband status } \\
\hline Negative & 5 \\
\hline
\end{tabular}

Table 3. Categories and sub-categories of study

\begin{tabular}{l|l}
\hline \multicolumn{1}{c|}{ Category } & \multicolumn{1}{c}{ Sub-category } \\
\hline \multirow{2}{*}{ Fear of rejection } & Rejection by partner \\
\cline { 2 - 2 } & Rejection by family \\
\hline \multirow{4}{*}{$\begin{array}{l}\text { Community construction } \\
\text { of HIV }\end{array}$} & Social stigma \\
\cline { 2 - 2 } & Discrimination in society \\
\cline { 2 - 2 } & $\begin{array}{l}\text { Traditional environment for } \\
\text { health services }\end{array}$ \\
\hline
\end{tabular}

This is the reason why many patients hide their condition. The fear of being rejected has two sub-categories: rejection by the partner and rejection by the family. 


\section{Rejection by partner}

One of the most important aspects of the reproductive health of women who are HIV positive, which affects not only them but also others and the community, is responsible behavior, which is one of the most effective methods to prevent the spread of the disease. Women with multiple sexual partners most often did not report their status to their sexual partner, and they did not insist on using condoms due to fear of being rejected.

"Although my partner is negative and I do not know if he has the disease, I did not tell him that I'm sick and I insisted on using a condom. I told him I cannot take pills and we should use a condom to prevent unwanted pregnancy and he complied, but if he refused after my insistence, I would have done nothing." (Participant No. 14).

Another participant, who had sexual high-risk behaviors and also a sexual relationship, disclosed the following about her sexual partner:

"I did not admit I am sick. If I do he will leave me; however, the one who transmitted the disease to me did not tell me (that he had AIDS). Therefore, I did not disclose my status to my current partner, it's not known who has got it from whom, I told him to use condoms, but the condom was too tricky and it got torn." (Participant No. 15).

\section{Rejection by family}

For many patients, when families are their aware of their status, their behavior towards them is extremely bad, and this causes mental problems and lack of support in infected people.

One of the participants contracted the disease through her husband, and the husband had a healthy child from his previous marriage, said: "All members of our families rejected us. My husband's family is very upset that I kept my husband's child and abuse me. I love this child I have raised. Since their discovery of my disease status, they've forced me to leave this kid, in order to hide the disease."

\section{Community construction about HIV}

Another category was community construction of HIV. Responsibilities of communities against AIDS have created a confidential environment on issues such as the disclosure of disease, the creation of a life without stigma and discrimination for patients. The stigma and consequence of discrimination are caused by interaction and social fabrication by the people, social networks and the larger social world in which they live and result from stereotyping. HIV is most often associated with stereotyping of people who are infected with the disease, such as the use of injectable drugs, homosexual men and unconventional sex; hence other infected people are also stigmatized, even if they are not in the mentioned stereotype classification [20]. Social stigma, discrimination in society and the traditional environment to provide health services are subcategories of this category.

\section{Discrimination in society}

Discrimination was a subcategory of community construction. Each participant experienced some forms of discrimination following the disclosure of their disease status, particularly discrimination by health professionals and doctors, who are expected to be the least discriminatory due to their level of knowledge and information about the disease, but unfortunately discrimination by staff and doctors was so great that many patients did not disclose their disease due to discrimination.

"I did not share my health status with the doctor. Once my husband went to a doctor because of his infectious teeth, the secretary said the price. When my husband talked about HIV, the secretary said that he should pay 3 times the money she had said before. My husband got angry, did not visit the doctor and extracted his teeth using pliers and he was in pain for a week. Now wherever I want to go, he tells me not to mention it to anyone, many doctors take advantage of our status for financial gain." (Participant No. 12).

Fear of disease-related consequences such as being fired from work, residence, and dismissal of a child from school were among other problems due to the spread of disease that infected people mentioned.

"I'm a janitor and if people in my workplace know I am sick they will fire me. This disease is a hassle, the only way to escape it is death." (Participant No. 1).

\section{Social stigma}

Another subcategory of community construction is social stigma. The disease-caused stigma is a major issue affecting the lives of infected women, so that many of them do not talk about their condition because they are afraid to disclose their disease even to their family.

"I am thinking when my child grows up, I will go abroad. You know, it's very difficult to live here. If you visit a doctor and say you are HIV-positive, they won't attend to you, for example, if they are specialists, they refer you to other doctors. People say better services are given abroad." (Participant No. 10).

One of the participant mentioned the role of media in increasing stigma. Most participants considered this as a responsibility of communities, as by providing the right information without fear through the media the stigma caused by the disease can be reduced.

"They are so bad in the media they never talked about the number of women who got the disease from tattoos. They talk about addiction and sex all the time. If this was not the case, no one would hide their disease." (Participant No. 11).

\section{Traditional environment for health services}

It is possible for people living in cities to disclose their disease due to environmental barriers, which results in several problems. Most of them travel to provincial centers to 
receive ART and care, and tolerate the difficulty of travel and lack of suitable accommodation which creates many problems for them.

"I'm going to Tehran to visit my doctor, because if I go to the counseling center in the city, everyone would discover my disease. Once they didn't give me my drugs and I went to the counseling center in the city but the counselor was my cousin and when I saw her I ran out but she followed me and took me and said she had been aware of our disease for two years but she had kept it a secret. I was very upset and I live with this nightmare. What should I do if my family discovers my status?" (Participant No. 10).

Another participant living in a small town said the following:

"Our city is very small, and very soon my disease would be known by all. That is why I have to go to Tehran to get drugs every month."

\section{Discussion}

One of the factors that are important in the spread of AIDS is the disclosure of the disease. In this study, most women who had a patient spouse had hidden their condition from their families, except when the family accidentally became aware of their condition. Women who did not have a spouse hid their condition from their sexual partners and their family. Most of women considered the role of society, especially the media, in increasing the fear of non-disclosure of the disease.

In a study conducted in South Africa in $2013,90 \%$ of the participants noted that, apart from health care providers, no one was aware of their condition, and women more often than men concealed their disease ( $93 \%$ vs. $86 \%$ ). The findings of this study showed that the spread of HIV is possible with the continued use of condoms, the willingness of pregnancy, and social support, but there are disadvantages in the light of potential positive and negative consequences. In a study on the factors contributing to the continued use of condoms was the disclosure of disease to the sexual partner. A study in Uganda showed that female patients who did not disclose their condition to their partner were less likely to use condoms [21]. Another study showed that those who consistently disclose their disease are less likely to participate in non-safe behaviors. Failure to disclose the disease is due to fear of being rejected by the partner. It is also possible that the sexual partner's financial support may be lost after the partner's discovery of the patient's condition [22]. Another issue was poor maintenance of the privacy for patients; most of them mentioned this as the reason for visiting centers outside their place of residence, as well as frequent referrals in counseling centers. In some cases, they were referred to the private sector, in which the patient did not disclose their disease, and exorbitant charges were requested by the physicians; also lack of visitation and inappropriate reaction of the doctor or the patient was mentioned as its main cause. A study in Kenya showed that most women presented to parental clinics because they were afraid of becoming stigmatized; in many cases especially lack of privacy was mentioned as the cause [23].
Of the cases that resulted in non-disclosure of the disease in this study there was AIDS-related stigma and discrimination. According to the quotations of participants, each participant had experienced some kind of stigma and discrimination. Many participants were very sad due to the reaction of people to the disease and their perceptions they had about the patients and also felt uncomfortable entering and leaving the behavioral counseling centers to the extent that they wanted to leave the country to live somewhere where nobody knew them or there was less stigma. In many societies, people with AIDS cannot find a suitable job because of the stigma, and this causes economic problems [24]. The results of a study on 1,200 HIV-positive people in Vietnam showed that most of them had experienced forms of discrimination, $44.4 \%$ ( 535 people) had experienced one type of discrimination, the average number of cases of discrimination was $6,34.3 \%$ reported sexual and reproductive health decision making, $14.9 \%$ had been disclosed without satisfaction, $2.5 \%$ had rejected the child due to their disease status and $12.5 \%$ were mentally harmed. Three percent of the people who were discriminated legally pursued the case, and the rest of them stated that the reason for not pursuing the case themselves was uncertainty as to the outcome of follow-up [25]. HIV/AIDS-caused stigma is a barrier to receiving HIV counseling and HIV tests [26]. Lack of education and awareness about the cause of the disease and its transmission pathways is one of the causes of discrimination and discrimination caused by the transmission of AIDS [27].

In some cases, the participants thought the fear of people who are infected was the role of the media and its negative impacts of giving wrong information on transmission methods focused on addiction and sexuality. Studies have shown that media, such as radio and television, play important roles in sending messages about health issues, especially those with cultural sensitivity. Many studies have shown meaningful relationships between the use of media and the reduction of the stigma caused by AIDS. Also, the results of a study in Ghana showed that the use of more TV reduces the risk of HIV in women. The results of these studies contradicted the experiences of people with HIV in the study, so that these people mentioned the cause of refusal to disclose their disease, media plans on the transmission of AIDS and the emphasis on transmission through sex and addiction. Therefore, promoting media programs which increase awareness about HIV and all kinds of transmission seems essential.

The disclosure of the disease requires the implementation of important policies, which include creating cognitive sensitivities for people living with HIV. Health care providers should note that disclosure of disease is not easy and aspects relating to disclosure of the disease, negative reactions to the spread of disease, and interventions should be improved to reduce negative reactions to the disclosure of disease. Training programs for communities and supportive groups should also be provided to reduce the incidence of HIV and improve the health of people with HIV. 


\section{Conclusions}

The results of this study showed that women with HIV have a lot of problems in disclosing their illness. Therefore, counseling interventions for patients with HIV can be helpful in disclosing the disease, as well as providing counseling services. Since discrimination was a barrier to the disclosure of illness in people affected, planning to raise awareness about AIDS and its transmission through the media and social networks, as well as educating health care providers and medical staff to respect the rights of infected people and advice on their confidentially, is essential.

\section{Conflict of interest}

The author's declared no potential conflicts of interest with respect to the research, authorship, and/or publication of this article.

\section{References}

1. Center for Disease Control and Prevention, Ministry of Health and Medical Education (Iran). Upublished AIDS data, 2017.

2. Behboodi-Moghadam Z, Nikbakht-Nasrabadi A, Ebadi A, et al. Fertility Desire in Iranian Women with HIV: A Qualitative Study. Iran J Public Health 2015; 44: 1126-1134.

3. Shacham E, Small E, Onen N, et al. Serostatus Disclosure Among Adults with HIV in the Era of HIV Therapy. AIDS Patient Care STDS 2012; 26: 29-35.

4. Amoran O. Predictors of disclosure of sero-status to sexual partners among people living with HIV/AIDS in Ogun State, Nigeria. Niger J Clin Pract 2012; 15: 385-390.

5. Adejumo AO. Perceived HIV stigmatization, HIV/AIDS cognition and personality as correlates of HIV self-disclosure among people living with HIV in Ibadan, Nigeria. Gender Behav 2011; 9: 3854-3869.

6. Saeieh SE, Nasrabadi AN, Ebadi A, et al. Contraception use among Iranian women with HIV: a qualitative study. Glob J Health Sci 2016; 8: 199-207.

7. Eustace RW, Ilagan PR. HIV disclosure among HIV positive individuals: a concept analysis. J Adv Nurs 2010; 66: 2094-2103.

8. Hardon A, Gomez GB, Vernooij E, et al. Do support groups members disclose less to their partners? The dynamics of HIV disclosure in four African countries. BMC Public Health 2013; 13: 589.

9. Kallem S, Renner L, Ghebremichael M, et al. Prevalence and pattern of disclosure of HIV status in HIV-infected children in Ghana. AIDS Behav 2011; 15: 1121-1127.

10. Kennedy CE, Medley AM, Sweat MD, et al. Behavioural interventions for HIV positive prevention in developing countries: a systematic review and meta-analysis. Bull World Health Organization 2010; 88: 615-623.

11. Wekesa E. A new lease of life: sexual and reproductive behaviour among PLWHA in the ART era in Nairobi slums: The London School of Economics and Political Science (LSE), 2012.

12. Chaudoir SR, Fisher JD, Simoni JM. Understanding HIV disclosure: A review and application of the Disclosure Processes Model. Soc Sci Med 2011; 72: 1618-1629.

13. Obermeyer CM, Osborn M. The utilization of testing and counseling for HIV: a review of the social and behavioral evidence. Am Journal Public Health 2007; 97: 1762-1774.

14. Shushtari ZJ, Sajjadi H, Forouzan AS, et al. Disclosure of HIV status and social support among people living with HIV. Iran Red Crescent Med J 2014; 16: e11856.
15. Kalichman SC, DiMarco M, Austin J, et al. Stress, social support, and HIV-status disclosure to family and friends among HIV-positive men and women. J Behav Med 2003; 26: 315-332.

16. Radfar SR, Sedaghat A, Banihashemi AT, et al. Behaviors influencing human immunodeficiency virus transmission in the context of positive prevention among people living with HIV/acquired immunodeficiency syndrome in Iran: a qualitative study. Int J Prev Med 2014; 5: 976-983.

17. Behboodi-Moghadam Z, Esmaelzadeh-Saeieh S, Ebadi A, et al. Development and Psychometric Evaluation of a Reproductive Health Assessment Scale for HIV-Positive Women. Shiraz E-Med J 2016; 17: e38489.

18. Graneheim UH, Lundman B. Qualitative content analysis in nursing research: concepts, procedures and measures to achieve trustworthiness. Nurse Educ Today 2004; 24: 105-112.

19. Guba EG. Criteria for assessing the trustworthiness of naturalistic inquiries. Educational Technology Research and Development 1981; 29: 75-91.

20. Goffman E. Stigma: Notes on a spoiled identity. Jenkins, JH \& Carpenter, 1963.

21. Wanyenze RK, Tumwesigye NM, Kindyomunda R, et al. Uptake of family planning methods and unplanned pregnancies among HIV-infected individuals: a cross-sectional survey among clients at HIV clinics in Uganda. J Int AIDS Society 2011; 14: 35.

22. Stutterheim SE, Shiripinda I, Bos AE, et al. HIV status disclosure among HIV-positive African and Afro-Caribbean people in the Netherlands. AIDS Care 2011; 23: 195-205.

23. Colombini M, Mutemwa R, Kivunaga J, et al. Experiences of stigma among women living with HIV attending sexual and reproductive health services in Kenya: a qualitative study. BMC Health Serv Res 2014; 14: 412 .

24. Kavanaugh ML, Moore AM, Akinyemi O, et al. Community attitudes towards childbearing and abortion among HIV-positive women in Nigeria and Zambia. Cult Health Sex 2013; 15: 160-174.

25. Messersmith LJ, Semrau K, Anh TL, et al. Women living with HIV in Vietnam: desire for children, use of sexual and reproductive health services, and advice from providers. Reprod Health Matters 2012; 20: 27-38.

26. Ayiga N, Nambooze H, Nalugo S, et al. The impact of HIV/AIDS stigma on HIV counseling and testing in a high HIV prevalence population in Uganda. African Health Sci 2013; 13: 278-286.

27. Dos Santos MM, Kruger P, Mellors SE, et al. An exploratory survey measuring stigma and discrimination experienced by people living with HIV/AIDS in South Africa: the People Living with HIV Stigma Index. BMC Public Health 2014; 14: 80. 